\title{
EFEKTIVITAS PENGGUNAAN METODE HIPNOSELF DALAM MENINGKATKAN KEPERCAYAAN DIRI MAHASISWA DI STIKES JENDRAL AHMAD YANI CIMAHI
}

\author{
Kharisma Danang Yuangga ${ }^{1 *}$, Janudin $^{2}$, I Nyoman Marayasa $^{3}$, Pranoto $^{4}$, \\ Ali Zaenal Abidin ${ }^{5}$ \\ ${ }^{1}$ Program Studi Pendidikan Ekonomi, Fakultas Keguruan Dan Ilmu Pendidikan, \\ Universitas Pamulang \\ 2,3,4,5 Program Studi Manajemen, Fakultas Ekonomi, Universitas Pamulang \\ Jl. Surya Kencana No.1, Pamulang Barat, Kec. Pamulang \\ Kota Tangerang Selatan, Banten 15417 \\ *Penulis Korespodensi: danangyuangga@gmail.com
}

\begin{abstract}
ABSTRAK
Tujuan dari kegiatan pengabdian kepada masyarakat ini adalah untuk menumbuhkan kepercayaan diri mahasiswa STIKES Jendral Ahmad Yani Cimahi. Selain itu juga untuk menggerakkan civitas akademik sekitar agar meningkatkan kepercayaan diri dalam kegiatan belajar dan dalam kehidupan sosial dengan sadar. Self-hypnosis juga sebaiknya tidak diajarkan pada klien yang bertujuan untuk mengungkap "fakta" yang tersimpan di memori pikiran bawah sadar. Memori bersifat rekonstruktif, bukan reproduktif. Dengan demikian, sama seperti dalam heterohypnosis, memori yang terungkap belum tentu akurat mengingat distorsi yang dapat terjadi pada memori.
\end{abstract}

Kata Kunci :Hipnosis, Hipnoself

\begin{abstract}
The purpose of community service activities is to foster the confidence of STIKES student General Ahmad Yani Cimahi. In addition, it is also to move the academic community around to increase self-confidence in learning activities and in social life consciously. Self-hypnosis should also not be taught to clients who aim to uncover the "facts" stored in the memory of the subconscious mind. Memory is reconstructive, not reproductive. Thus, as in heterohypnosis, the revealed memory is not necessarily accurate given the distortion that can occur in memory.
\end{abstract}

Keywords: Hypnosis, Hipnoself

\section{PENDAHULUAN}

Seseorang bisa dikatakan percaya diri ketika memiliki keyakinan atas kemampuannya sendiri (Sunarsi, D., \& Asmalah, L. 2018). Namun meningkatkan percaya diri bukanlah kemampuan yang datang dengan sendirinya, melainkan harus 
dilatih. Keyakinan pada diri sendiri ini penting untuk kesehatan mental seseorang, lho. Sebab kalau tidak percaya diri, susah meraih kesuksesan dan kebahagiaan personal maupun profesional.

Mengacu pada situs Forbes, keterbatasan kerap menjadi pengekang seseorang untuk maju dan ragu mencoba hal baru. Perasaan takut gagal karena merasa kurang mampu diakibatkan tidak adanya percaya diri. Riset yang dilakukan William James menyebut tidak berkembangnya potensi bukan hanya disebabkan minim kecerdasan dan kesempatan, melainkan karena pesimisme. Nyatanya, kepercayaan diri tidak didapat begitu saja, melainkan dibangun (Putra, Yovan P., 2015). Berbekal kepercayaan diri, memperbesar peluang untuk membuka harapan-harapan baru, seperti diterima pekerjaan, terealisasinya keinginan yang belum tercapai, maupun meningkatkan produktivitas (Fricker, Janet; Butler, John, 2015)

Ketika seseorang percaya atas kemampuan dirinya, akan mudah untuk melakukan sesuatu hal yang baru dan menaruh semua energinya untuk hal tersebut (Olness, Karen; Kohen, Daniel P, 2016). Misalnya, ketika mendaftar pekerjaan, seseorang akan yakin bahwa dirinya mampu atas semua tanggung jawab yang dibebankan pada posisi yang dilamarnya. Atau ketika merasa percaya diri akan melakukan presentasi maka akan fokus untuk menyampaikan seluruh materinya kepada audiens dan menampilkan yang terbaik, bukannya malah sibuk mencemaskan keterbatasan dirinya.

Identifikasi masalah yang ditemukan di lapangan adalah masih kurangnya motivasi dalam menumbuhkan rasa kepercayaan diri pada mahasiswa. Peningkatan ras percaya diri pada kegiatan ini akan menggunakan pengaplikasian hipnoself sebagai bentuk dari penerapan hipnoterapi dalam kehidupan sehari-hari. Secara umum mekanisme kerja hipnoself dan hypnotherapy sangat terkait dengan aktivitas otak manusia. Aktivitas ini sangat beragam pada setiap kondisi yang diindikasikan melalui gelombang otak yang dapat diukur menggunakan alat bantu EEG (Electroenchepalograph).

Kegiatan pengabdian kepada masyarakat dari tim dosen dan mahasiswa Universitas Pamulang hadir di STIKES Jendral Ahmad Yani Cimahi, serta berbagi pengetahuan dan wawasan dengan bentuk penyuluhan yang menggunakan teknik hipnoself untuk meningkatkan kepercayaan diri mahasiswa. Penyuluhan yang bertujuan menumbuhkan kepercayaan diri dalam diri mahasiswa ini semata-mata untuk membangun mental positif dan optimism, terutama memiliki rasa percaya pada diri sendiri yang tentunya akan menjadi modal yang kuat dalam mencapai cita-cita di masa yang akan datang.

Tim pengusul pengabdian kepada masyarakat berharap respon dan antusias civitas akademika, khususnya mahasiswa STIKES Jendral Ahmad Yani Cimahi dalam membentuk kepercayaan diri Sehingga kegiatan pengabdian kepada masyarakat tidak hanya berhenti pada kegiatan penyuluhan ini tetapi dapat berkelanjutan sesuai kebutuhan mahasiswa, terutama yang berkaitan dengan pengembangan karakter sebagai bentuk kepedulian terhadap diri sendiri dan rencana karirnya di masa depan. 
Kharisma Danang Yuangga, dkk

\section{METODE PELAKSANAAN}

Metode pelaksanaan memaparkan tahapan yang perlu dilakukan mulai dari perencanaan/ pengusulan hingga pelaporan dalam serangkaian kegiatan pelaksanaan pengabdian kepada masyarakat. Metode pelaksanaan dalam kegiatan pengabdian kepada masyarakat ini diawali dengan melakukan survey lokasi di STIKER Jendral Ahmad Yani Cimahi atas ketertarikan tim pengusul berdasarkan pengamatan seharihari, terutama saat pembelajaran dan menyampaikan pendapat di kelas, juga berinteraksi dalam kegiatan sosial.

Instruktur dalam menyampaikan penjelasan juga memasukkan unsur "sharing" atau berbagi pengalaman mengenai penggunaan hipnoself dalam menumbuhkan kepercayaan diri yang dimiliki trainer sehingga dapat memberikan gambaran lebih jelas kepada peserta. Pada metodepraktik, peserta berkelompok dan dengan pendampingan trainer mahasiswa bergantian melakukan hipnoself dan mensugesti secara bergantian berkaitan dengan temannya. Peserta diajarkan bagaiman acara meyakinkan diri dengan membuka alam bawah sadar untuk membentuk image diri yang lebih percaya diri.

\section{HASIL DAN PEMBAHASAN}

Peserta yang hadir sebanyak 40 mahasiswa STIKES Jendral Achmad Yani. Peserta adalah mahasiswa yang notabene terindikasi memiliki kepercayaan diri yang rendah. Sebanyak 15 mahasiswa memeiliki kecemasan yang tidak beralasan, sehingga mereka cenderung malu untuk berbicara dengan banyak orang. 3 Peserta lain memiliki masalah kurang percaya diri dengan penampilan, sedangkan sisanya memiliki kecenderungan untuk minder jika harus berbicara atau berinteaksi dengan banyak orang.. Selain menganggap penggunaan teknik hipnoself cukup sulit, mereka juga merasa tidak banyak transaksi aktual yang terjadi dibandingkan dengan berinteraksi langsung. Sebanyak 20 orang peserta lainnya belum pernah secara intensif berinteaksi di depan kelas. Mereka enggan untuk mencoba karena minder, meski ada pula yang merasa memiliki rasa percaya diri, namun masih belum mau berusaha.

Mereka mayoritas lebih nyaman berinteraksi dengan sedikit orang yang mereka kenal, dan menggunakan aplikasi seperti Whatsapp untuk berkoordinasi dalam forum yang lebih besar, meskipun dengan cara tersebut tidak banyak membuat mereka berani berinteraksi dengan aktif.

Teknik Hipnoself (Self-hypnosis), bila mampu dilakukan dengan benar, sangat banyak manfaatnya. Saat seseorang dalam kondisi hipnosis, tubuhnya mengalami respon relaksasi yang sangat baik untuk kesehatan. Penelitian tentang respon relaksasi ini telah dilakukan secara intensif oleh Herbert Benson dari Harvard Medical School.

Untuk tujuan terapi diri, self-hypnosis, dalam pengertian sebagai upaya swadaya untuk masuk kondisi hipnosis, tidak terapeutik. Kondisi hipnosis per se tidak bersifat terapeutik, namun adalah prasyarat untuk bisa melakukan teknik-teknik penyembuhan secara efektif yang melibatkan pikiran bawah sadar. Untuk bisa melakukan penyembuhan diri swadaya membutuhkan teknik yang sesuai dengan kondisi yang hendak diatasi, seperti mahasiswa STIKES Jendral Achmad Yani di Cimahi yang memiliki permasalahan dengan rasa percaya diri yang rendah.

Ada banyak trainer atau lembaga yang mengajarkan self-hypnosis, masingmasing dengan durasi pelatihan dan kurikulum yang berbeda. Artikel ini tidak 
bertujuan untuk menunjuk langsung atau merekomendasikan pelatihan mana yang sebaiknya diikuti. Ada beberapa syarat yang perlu dipenuhi agar satu pelatihan dikatakan baik dalam konteks mengajarkan self-hypnosis.

Syarat ini antara lain, pertama, pengajarnya adalah seorang hipnoterapis klinis yang aktif menangani klien di ruang terapi. Syarat pertama ini mutlak perlu dipenuhi mengingat trainer yang baik adalah trainer yang praktisi, bukan teoris. Kedua, dalam pelatihan dijelaskan detil tentang landasan teoretik yang digunakan trainer mengajar self-hypnosis, cara kerja pikiran sadar dan bawah sadar, apa itu kondisi hipnosis, bagaimana cara mencapai kondisi ini, apa saja ukuran baku untuk mengetahui dan memastikan seseorang telah masuk kedalaman kondisi hipnosis tertentu. Akan sangat baik bila trainer memiliki alat ukur guna membuktikan secara kuantitatif kondisi hipnosis yang dicapai peserta. Ketiga, teknik self-hypnosis yang diajarkan mampu membawa peserta dengan tipe sugestibilitas berbeda untuk bisa masuk kondisi hipnosis. Ini sangat penting mengingat sering dijumpai peserta pelatihan yang tidak bisa masuk kondisi hipnosis karena teknik yang diajarkan tidak efektif. Keempat, peserta mendapatkan teknik-teknik self-healing yang telah teruji secara klinis efektif untuk mengatasi masalah.

Dari berbagai literatur dan juga pengalaman klinis dapat disimpulkan bahwa untuk memelajari self-hypnosis secara mendalam tidak mungkin dilakukan hanya dalam dua atau tiga jam. Selain perlu mendapat uraian mendalam tentang teori dan teknik, para peserta juga perlu berlatih, di tempat pelatihan, untuk bisa masuk ke kondisi hipnosis sendiri. Dan di tahap awal ini tentu butuh bimbingan dan bantuan trainer.

\section{PENUTUP}

Hasil kegiatan PKM di STIKES Jendral Achmad Yani di Cimahi berjalan dengan lancar. Mahasiswa terlihat antusias mempelajari teknik hipnoself untuk meningkatkan kepercayaan dirinya. Selain itu penggunaan teknik hipnoself dapat memberikan kemudahan mahasiswa dalam memberikan sugesti dan motivsi diri untuk dapat lebih yakin dalam membangun rasa percaya diri dalam dirinya. Sehingga diharapkan akan memberikan dampak di masa yang akan datang, seperti lebih mantab dalam menghadapi persiapan memasuki dunia kerja selepas kuliah. Mahasiswa memperoleh ilmu pengetahuan baru, sehingga bisa dimaksimalkan potensi diri dengan berfikir inovatif dan kreatif.

\section{DAFTAR PUSTAKA}

Burrows, Graham D.; Stanley, Robb O.; Bloom, Peter B.International Handbook of Clinical Hypnosis ISBN 0-471-97009-3.

Fricker, Janet; Butler, John; Secrets of Hypnotherapy ISBN 0-7513-1203-7

M Catio, D Sunarsi. (2020). Analisa Pengaruh Kompetensi, Disiplin Kerja Dan Motivasi Terhadap Kinerja Guru Pada SMK Sasmita Jaya 1 Pamulang Kota Tangerang Selatan. Equilibrium: Jurnal Penelitian Pendidikan dan Ekonomi 17 (02), 16-26 
Kharisma Danang Yuangga, dkk

Olness, Karen; Kohen, Daniel P. Hypnosis and Hypnotherapy With Children ISBN 157230-054-X

Putra, Yovan P. (2015). ;Rahasia di balik Hipnosis Ericksonian dan metode pengembangan pikiran lainnya ISBN 978-979-27-7961-5

Roswendi, A. S., \& Sunarsi, D. (2020). Dinamika dan Perkembangan Hypnotherapy Dalam Perspektif Interdisipliner. Cilegon: Runzune Sapta Konsultan

Sunarsi, D, et.al (2020). Menatap Wajah Pendidikan Indonesia Di Era 4.0: A Book Chapter of Indonesian Lecturer Associations. Kota Serang: Desanta Muliavisitama

Sunarsi, D. (2020). Panduan Meningkatkan Kinerja Dan Kepuasan Guru. Kota Serang: Desanta Muliavisitama

Sunarsi, D., \& Asmalah, L. (2018). Pelatihan Manajemen Pengembangan Diri Bagi Penerima Beasiswa RZIS UGM Dan Dompet Shalahuddin Jogjakarta. Jurnal Pengabdian Dharma Laksana, 1(1), 51-60.

Sunarsi, D., Kustini, E., Lutfi, A. M., Fauzi, R. D., \& Noryani, N. (2019). Penyuluhan Wirausaha Home Industry Untuk Meningkatkan Ekonomi Keluarga Dengan Daur Ulang Barang Bekas. BAKTIMAS: Jurnal Pengabdian pada Masyarakat, 1(4), 188-193. 